\title{
Emenda ao orçamento $\left.{ }^{*}\right)$
}

\section{E' possivel emendar o orçamento após encerrado o praso constitucional de sua elaboração legislativa?}

\section{Theotonio Monteiro de Barros Filho}

\section{I - Da legitimidade da arrecadação}

O artigo 27 do decreto federal $n^{\circ} 4.536$, de 28 de janeiro de 1922, que organizou o Código de Contabilidade da União dispunha o seguinte:

"A arrecadação da receita proveniente de imposto dependerá sempre da inserção desta na lei de orçamento. Qualquer outra fonte de receita, porém, criada em lei ordinária, deverá ser arrecadada, embóra não contemplada na referida lei do orçamento."

Por seu lado, o Regulamento Geral de Contabilidade Publica, aprovado pelo decreto federal n. ${ }^{\circ} 15.783$, de 8 de novembro de 1922, baixado para aplicação do Código de Contabilidade da União, reitera o assunto no seu artigo 133:

"Toda receita deve ser inscrita na lei de orçamento, sem que, entretanto, para aquela que não tenha sido na mesma compreendida, se entenda

( ${ }^{*}$ Estudo feito a pedido da Federação do Comércio de São Paulo e da Associação Comercial de São Paulo, a propósito do aumento do Imposto de vendas e consignações. 
prejudicado o direito do Estado de arrecada-la, nem eximidas as repartições competentes de procederem ao respectivo lançamento e arrecadação. $E \boldsymbol{x}$ cetua-se desta última parte a receita proveniente de imposto, cuja arrecadação dependerá sempre da inserção deste na lei do orçamento."

A legislação é, pois, de clareza meridiana no tocante à exigência da inserção dos impostos na lei orçamentaria, para que seja legitima a sua arrecadação. E, como se vê pelas datas, não se trata de um principio novo no nosso Direito Público. Ha, pelo menos, um pouco mais de vinte e cinco anos que ele é vigente.

Sobrevindo a Constituição de 1946, o principio consagrado pelos dispositivos legais acima citados foi alargado, para o efeito de abranger não só os impostos, mas todas as receitas tributarias, cirstalisando-se na norma constitucional do $\S 34$ do artigo 141 da Lei Basica, elevado assim à dignidade de garantia individual.

Poder-se-iam formular reservas quanto ao alargamento feito, porque em verdade a aplicação rigorosa desse principio no que se refere às taxas e a outros tributos de naturesa corporativa, poderá acarretar dificuldades de ordem pratica. Mas quanto ao imposto, não ha a menor dúvida de que a Constituição de 1946 andou com o maior acerto em converter numa garantia individual a autorisação orçamentaria como requisito essencial à validade de sua exigencia. Trata-se, no fundo, de completar as garantias dadas ao direito de propriedade (artigo $141 \S 16$ ), que só pode ser afetado pela desapropriação fundada em necessidade ou utilidade publica ou interesse social, mediante prévia e justa indenisação. $O$ imposto, seja quando atinge o capital, seja ao atingir qualquer das formas do redito, o que está na realidade alcançando sempre é a propriedade em si mesma. De nada valeriam, portanto, quaisquer garantias dadas a esta última sob outros aspectos, se se dei- 
xasse a porta aberta para o confisco sob a forma de tributação arbitraria. Os $\S \S 16$ e 34 do artigo 141 da Constituição Federal são, portanto, normas que se completam, no sentido de assegurar a estabilidade de um direito que está na base da estrutura economico-juridico-politica dos países de civilisação ocidental.

Em verdade o citado $\S 34$ do artigo 141 da atual Constituição não é senão a ultima forma evolutiva de um principio pelo qual os homens vêm lutando ha séculos. Foi ha pouco mais de sete seculos que essa luta entrou a manifestar-se mais intensa, atravessando por vezes fases cruentas, e arrastando na sua esteira, como conquistas arrancadas ao poder arbitrario dos reis, quasi todas as franquias publicas que hoje asseguram a liberdade e os demais direitos fundamentais da criatura humana. Por causa de exigencias fiscais tiranicas e desordenadas, o principe João, na Inglaterra, teve de enfrentar os seus barôes, aliados ao povo, no ano de 1215. E sob pressão teve de aceitar aquele preceito legal figurante na Magna Carta: "No scutage or aid shall be imposed in the kingdom, unless by the Common Council of the realm", sendo certo que o "Common Council", não muito tempo após a assinatura da Magna Carta, veio a transformar-se no Parlamento, expressão da vontade popular. Obrigado a ouvir os seus barões e, de um modo geral, os seus súditos, através do Parlamento, o poder real inglez continuou, entretanto, a luta para exercer prerrogativas tributarias independentemente de autorização dos Comuns. E no decurso desses sete seculos que nos separam do ano longinquo de 1215, James I perdeu seu trono e Carlos I a sua cabeça, em razão de desrespeitos por eles praticados às regras tributarias tendentes a cobrir os contribuintes contra o arbitrio. (Vide Buck - "Budget in Governments of Today", ed. de The Macmilian Co. N. Y., 1934, pags. 6/45 e tambem Stourm "Le Budget", ed. Gullaumin \& Cie., Paris, 1889 - capitulos I e II). Ao deflagar-se a Revolução Franceza, esse tremen- 
do sorvedouro de vidas, através do qual a França, com o sacrificio de suas elites, firmou definitivamente os principios juridicos e politicos que haviam de presidir a evolução historica dos povos ocidentais nestes ultimos cento e cincoenta anos, o imposto se tornou contribuição consentida pelos cidadãos através dos orgãos de representação popular, sendo certo que a igualdade de todos perante a lei - extensiva à lei fiscal - acabou com todos os privilegios e isenções pre-existentes, limitando muito as possibilidades de arbitrio e de iniquidade no campo tributario.

Vê-se do exposto que, por causa mesmo do apego do homem aos seus bens e da intensidade do sentimento de propriedade, a luta contra a arbitrariedade fiscal tem sido uma das preocupações dominantes da Humanidade durante séculos. E quem examina em pormenor os lances por vezes dramaticos dessa luta, verifica que a primeira con quista popular firmada, neste terreno, foi a de não se considerarem legitimos tributos arrecadados pelo poder real sem autorisação do povo. De todo o conjunto de medidas que hoje asseguram os cidadãos nos países civilizados contra os excessos fiscais, o condicionamento da validade da arrecadação a uma autorisação prévia (que hoje é dada no orçamento) é a mais antiga, porque tendo sido considerada como a mais importante, foi a primeira a ser reclamada pelos povos.

O legislador constituinte de 1946 mostrou, pois, grande sabedoria e apreciavel cultura, quando reconheceu em antigos dispositivos perdidos na nossa legislação ordinaria anterior o valor e a importância de preceitos basicos da estrutura economica, juridica e politica que adotamos. Qualquer atentado contra o $\S 34$ do artigo 141 da Constituição Federal se reveste, portanto, da mais alta gravidade, porque atinge o proprio amago do conjunto de garantias com que o Poder Soberano cobriu o cidadão, quando se auto-limitou constitucionalmente. 
Ora, o citado $\S 34$ do artigo 141 da Constituição subordina a legitimidade da arrecadação de quaisquer tributos (isto é, impostos, taxas e contribuições especiais) a duas condições essenciais :

a) que o tributo a ser arrecadado tenha sido criado ou aumentado por lei;

b) que a arrecadação esteja expressamente autorisada pelo orçamento do ano financeiro, salvo para o caso de impostos de guerra ou direitos aduaneiros.

Estas duas condições de legalidade da arrecadação, instituidas como garantias individuais, não foram hierarquisadas pela Constituição. Ela as estabeleceu em pé de igualdade, para atuarem juntas, sob pena de não se inte-grar a situação de legalidade da exigencia do tributo.

Logo, qualquer interpretação que redunde em autorisar a dispensa de um desses dois requisitos igualmente essenciais, para o efeito de se considerar como valida exigencia fiscal formulada sem a presença de um deles, é interpretação erronea, perigosa e gravemente nociva aos proprios fundamentos da nossa estrutura juridico-politica de natureza democratica.

Estando aprovado pelo poder legislativo estadual, dentro do praso legal, e tendo sido devidamente sancionado e publicado, o orçamento do Estado de São Paulo para o ano de 1949 só contempla autorização para arrecadar-se o imposto de vendas e consignações na base da alíquota fixada pela lei anterior à referida autorização orçamentaria. Quaisquer alterações dessa aliquota para mais, feitas posteriormente à aprovação e publicação do orçamento, e por isso mesmo nele não contempladas, só poderão ser vigentes e ter condições de exigibilidade em exercicios ulteriores a 1949, para os quais os respectivos orçamentos consignem a imprescindivel autorisação. 
lnutil acrescentar que a Constituição estadual de São Paulo, quanto aos impostos - e é de imposto que no caso se trata - encerra, no seu artigo 63, dispositivo abšolutamente igual ao do $\S 34$ do artigo 141 da Carta Federal. De modo que nem ao menos se poderia pretender invocar - o que, de resto, seria inoperante - qualquer discrepancia entre a lei basica federal e a estadual, neste passo.

Assim, a menos que se admita a possibilidade da emenda do orçamento, depois de votado pelo Congresso (ou Assembléia Legislativa), e de sancionado e publicado pelo Executivo, não será possivel a arrecadação de quaisquer tributos criados ou aumentados por lei de data posterior ao dito orçamento.

\section{II - Da emenda ao orçamento}

Põe-se, então o problema: será o orçamento emendavel validamente, depois de vencido o praso dado pela Constituição ao Poder Legislativo para a aprovação do mesmo, já estando ele sancionado e publicado?

Não vacilamos em responder pela negativa. A nosso vêr, uma vez publicado, estando encerrado o praso de competencia orçamentaria constitucional do Legislativo, o orçamento não tolera mais emendas que lhe alterem a substancia, ampliando para mais a receita ou a despesa.

No que tange à receita tributaria, o orçamento obriga com força de lei o Executivo a aplicar toda a sua diligencia, no sentido da realĩzação integral; e em relação ao contribuinte, indica o limite de pressão tributaria a que ele vai ser submetido, durante $o$ ano financeiro a que o orçamento se refere. Estabelece-se, dest'arte, quanto à receita, uma situação de direito que se torna perfeita, desde o momento da aprovação e publicação do orçamento, situação essa que, de um lado, obriga e limita a ação do Estado, enquanto que, de outro, cobre o contribuinte contra surpresas e arbitrios, assumindo o carater de uma garantia individual. 
Já no que diz com a despesa, diferente é o efeito do orçamento. Para o Executivo, o orçamento da despesa não envolve uma obrigação de execução, mas tão sómente uma autorização e um limite. Ele significa que, no ano financeiro, a despesa maxima possivel é aquela consignada, mas não quer dizer que tal despeza (como acontece com a receita) deva ser obrigatoriamente realizada.

Vê-se daí que, quando se admitisse a possibilidade de emenda do orçamento, seria sempre muito grave alterarIhe a parte referente à receita, porque esta, - uma vez alterada para mais - teria que ser realisada, visto que o Executivo fica obrigado a arrecadar a receita votada, ainda que para tanto tenha de empregar meios coercitivos, através da cobrança judicial. Assim, pondo-se de lado consequencias de natureza financeira e economica que o fato poderia ter, para só fixarmos em toda a sua pureza o aspecto exclusivamente juridico, não vacilariamos em dizer que a possibilidade de emenda à receita constitúe ameaça mais grave aos direitos individuais do que a possibilidade de emendar-se a despeza.

A verdade, entretanto, é que tendo em vista os pessimos resultados tanto de uma como de outra emenda, as praticas orçamentarias mundiais e as leis - estas ultimas senão explicita, pelo menos implicitamente, — as tem procurado vedar.

Dir-se-á que nenhum dispositivo legal federal ou do Estado proíbe taxativamente a emenda ao orçamento. Sim, é certo. Mas tal proibição resulta clara dos elementos interpretativos seguintes:

1) A anualidade do orçamento. A Constituição Federal de 1946 não diz expressamente que o orçamento será vigente por um ano. Mas de inumeras passagens de seu texto resulta essa conclusão. Assim é que no artigo 87, inciso XVI, figura como atribuição do Presidente da Republica a remessa da proposta de orçamento à Camara dos Deputados, dentro dos primeiros dois meses da sessão legislativa; por outro lado, cabe aos orgãos de representação po- 
pular e federativa enviar o orçamento à sanção até o dia 30 de novembro, sob pena de ser prorrogado o do ano anterior (Const. fed. art. 74). Estas duas remissões ao texto constitucional, às quais se poderiam ajuntar varias outras, bastam para demonstrar que o orçamento federal brasileiro é anuo. Por outro lado, o decreto federal $n .^{\circ}$ 4.536 , de 28 de janeiro de 1922, que organisou o Codigo de Contabilidade da União e o decreto n. $^{\circ} 15.783$, de 8 de novembro de 1922, que deu regulamentação geral à contabilidade publica, respectivamente nos seus artigos $8 .^{\circ}$ e seguintes e 26 e seguintes, são explicitos no sentido da anualidade orçamentaria, estando tais decretos em vigor, porque não colidem com a Constituição vigente. $\mathrm{E}$, no ambito estadual, essa mesma regra de anualidade é explicita no artigo $8 .^{\circ}$ do decreto $\mathrm{n} .^{\circ} 2.416$, através do qual o poder federal padronisou normas financeiras e contabeis para os Estados (dec. fed. n..$^{\circ} .416$ de 17 de julho de 1940), resultando tambem implicita dos dispositivos contidos nos artigos 29 e 32 da Constituição estadual.

De resto, essa regra é praticamente universal. Poucos são os casos de exceção citados pelos autores, em que raros países têm ensaiado para os respectivos orçamentos periodos maiores de um ano.

Isto posto, é de se perguntar: qual o objetivo da regra de anualidade do orçamento?

Ora, a resposta é simples. Olhado do ponto de vista do Estado, o orçamento é um plano de administração. Muitos autores assim o definem expressamente, sendo mesmo comum considerarem-no como o mais importante dos atos administrativos de cada ano, visto conter em seu bôjo todas as providencias a executar, todas as obras a realizar, toda a vida estatal a ser desenvolvida, paralelamente com os recursos necessarios a tudo isso. Mas um plano pressupõe: a) um objetivo a alcançar; b) recursos materiais e tecnicos indispensaveis à realização de dito objetivo; c) um lapso de tempo, dentro do qual o agente, tendo em vista 
o objetivo, ponha em ação os recursos e a técnica. Assim, em qualquer plano, o tempo aparece como elemento essencial integrante do conceito. Não raro mesmo os planos são designados pela sua duração: plano quinquenal, plano bienal, etc. E' o fator tempo que, nos planos, exprime a necessaria estabilidade de determinadas diretrizes e objetivos, assim como de certas condições propiciadoras, para que os fins possam ser alcançados. Na idéia de plano está, portanto, contida a da estabilidade temporaria de certos elementos. E' indispensavel à realização dos fins estatais a certeza de que, durante um preciso lapso, o Poder Publico contará com determinados recursos para a realização de obejtivos préviamente escolhidos, de acordo com as necessidades coletivas mais prementes. Como, porém, a economia publica está estreitamente ligada à economia privada, funcionando esta como fonte abastecedora daquela, e sendo certo que a vida economica se caracteriza pela presença de permanentes flutuações, a prudencia manda que o dado temporal integrante dos planos orçamentarios seja de curta duração, afim de que variações mais ou menos acentuadas da conjuntura não venham a impedir a obtenção de recursos necessarios. E' por isso que quasi universalmente se adota o lapso de um ano para vigencia dos orçamentos.

Do ponto-de-vista do Estado, pois, são principalmente razões de ordem economica, alem de outras, que aconselham a adoção do prazo anuo para o orçamento.

Mas quando olhamos o problema sob o prisma do interesse do contribuinte, verificamos que ha razões juridicas da mais alta relevância, acrescentadas às de ordem economica, para que os orçamentos funcionem dentro de um lapso de tempo estabelecido pela lei. Essas razões visam principalmente cobrir o contribuinte contra a surpresa e contra o arbitrio do Fisco. Sabendo que o plano será vigente por um periodo certo, o contribuinte organisa suas atividades privadas com base nos encargos previamente 
conhecidos, os quais não poderão ser acrescidos de outros dentro dessa fase. Fica assim o cidadão a salvo de exações intempestivas, imprevistas e gravosas, capazes de colhe-lo durante o desenvolvimento de um programa organizado com dados economicos com antecedencia analisados e ponderados.

Vê-se do exposto que tanto para o Estado, como para os particulares, razões juridicas se emparelham com outras economicas para indicar que, durante o periodo de um ano, adotado pela lei para a duração do orçamento, este constitue uma situação estavel, dentro da qual o Estado conhece os elementos com que conta para realizar objetivos planejados e o contribuinte, por seu lado, se sente assegurado contra surpresas desagradaveis no setor do seu patrimonio, provenientes de exigencias tributarias.

Foi atendendo especialmente ao interesse do contribuinte no problema que a Constituição Federal inseriu a condição da autorização anua para a exigencia valida de quaisquer tributos. Quando o $\S 34$ do artigo 141, da Constituição Federal (Const. est. art. 63) estabelece que é essencial autorisação orçamentaria para que o imposto seja i eclamado, o que ele está no fundo dizendo é que, durante um ano, só aqueles impostos consignados no orçamento votado e publicado poderão ser validamente reclamados (salvo o direito aduaneiro e o imposto de guerra). Ha aí a presença do elemento tempo (um ano; por força da regra da anualidade orçamentaria), destinada a assegurar a estabilidade de condições necessarias à realização dos planos e, paralelamente com isso, a cobrir os cidadãos contra quaisquer surpresas.

Não ha dúvida, pois, de que o orçamento traduz uma situação de direito que a lei deseja estavel por um ano, tanto para o Estado, como para o contribuinte, embora por motivos algo diferentes.

Dentro desta idéia, não é possivel admitir-se a faculdade de emenda ao orçamento. A emenda seria a quebra 
da estabilidade temporaria desejada pela lei; seria tambem o ensejo para agravações da situação do contribuinte, feitas de surpresa.

Mas isso não é tudo.

2) A regra de prorrogação do orçamento vigente, contida no artigo 74 da Constituição Federal e reproduzida no artigo 32 da Constituição estadual é de importância capital, no sentido de esclarecer a impossibilidade de emenda do orçamento, depois de votado e publicado.

Que diz o artigo 32 da Constituição de São Paulo?

"Se o orçamento não fôr enviado à sanção até o dia 14 de novembro, ficará de pleno direito prorrogado o do exercicio vigente."

Portanto, "compete à Assembléia votar o orçamento e legislar sobre tributação" (Const. est., art. 20, "b"), mas tal competencia, relativa à materia orçamentaria, Só EXISTE E Só PODE ATUAR ATÉ O DIA 14 DE NOVEMBRO DE CADA ANO. Se até esse dia ela foi exercida, o ato é valido e produz todos os seus efeitos, porque praticado no termo; se não foi exercida, ESTÁ EXTINTA, EM RELAÇ.̃̃O AO ANO FINANCEIRO IMEDIATO, NÃO ASSISTINDO MAIS AO LEGISLATIVO QUALQUER POSSIBILIDADE DE AÇÃOO.

A data de 14 de novembro é, pois, na Constituição Estadual (art. 32), tal qual como o dia 30 de novembro na Federal (art. 74), UM TERMO FINAL. Aí se vê a Lei Magna marcando a um dos Poderes um prazo para exercitar certa competencia, sob pena de não poder mais exerce-la, isto é, sob pena de decair de sua prerrogativa.

Que não se estranhe o fato de invocarmos aqui, em pleno campo do Direito Publico, um instituto juridico figurante no Código Civil, portanto num Código de Direito Privado (Cod. Civil, arts. 119 e 124 combinados). O gran. de Hauriou, a outro proposito, já estudou diversas aplicações de regras de Direito Privado a problemas do Direito Administrativo (Direito Publico, portanto), conforme se vê 
de seu interessante trabalho inserto a fls. 92 do "Recueil d'Études sur les Sources du Droit, en l'honneur de FrançoIs GenY”, ed. de Recueil Sirey, Paris, sem data, vol. III. Por outro lado, é certo que o Código Civil está cheio de normas a respeito das quais a vontade das partes nada pode, o que é bem caracteristico das regras do Direito Publico.

Feita esta advertencia, vejamos o que é o termo final. "Ao termo inicial se aplica o disposto, quanto à condição suspensiva, nos artigos 121 e 122 , e ao termo final, o disposto acerca da condição resolutiva do artigo 119" (Cod. Civ. art. 124).

"Se fôr resolutiva a condição, enquanto esta não se realisar, vigorará o ato juridico, podendo exercer-se desde o momento deste o direito por ele estabelecido; mas, verificando-se a condição, para todos os efeitos, SE EXTINGUE O DIREITO A QUE ELA SE OPôE" (Cod. Civ., art. 119).

Desse termo final resolutivo dá-nos bem clara idéia o grande Planiol, ao estudar o que os francezes chamam "délai préfix":

“... le délai préfix est donné par la loi pour accomplir un acte déterminé, qui ne peut être fait que dans le délai fixé, de sorte qu'en cas de rétard l'intéressé est forclos, et ne peut plus faire utilement l'acte d'où dépendait la conservation de son droit ou la protection de ses interêts. Le délai préfix diffère donc de la prescription par son but. Les délais préfix diffèrent encore de la prescription en ce qu'ils ne sont pas susceptibles d'être allongés ni par une cause de suspension ni par un acte interruptif. Ils courent donc contre tout le monde et s'accomplissent fatalement à l'heure dite. La seule prorrogation dont ils soient susceptibles est ce qu'on appelle délai de distance quand l'inte- 
réssé réside au loin (art. 73 et 445 C. proc. civ.)". (Planiol - "Droit Civil", ed. de la Librairie Generale de Droit \& Jurisprudence, Paris, 1923, vol. II, n. ${ }^{\circ} 704$, pg. 229).

Isto posto, vê-se bem que a Constituição do Estado, em seu artigo 32, colocou a Assembléia Legislativa em face de um termo final resolutivo (délai préfix), constituido pelo dia 14 de novembro. Se até esse dia a Assembléia exerceu o seu direito de votar o orçamento (direito que é tambem um dever, porque a prerrogativa orçamentaria é, em alguns de seus aspectos, entrelaçada com as garantias individuais), o orçamento ESTÁ VALIDAMENTE VOTADO, subindo à sanção. Se não exerceu a Assembléia esse direito, NÃO O PODE MAIS EXERCER, PORQUE O PRAZO É RESOLUTIVO E EXTINGUE O DIREITO. A verdade, portanto, é que, de uma forma ou de outra, a 14 de novembro de cada ano, a competência orçamentaria da Assembléia Legislativa, em relação ao ano financeiro que se segue, se extingue completamente. Se ela foi exercida, exaure-se, ficando valido o ato praticado (o orçamento); se não foi exercida, não o pode mais ser, porque o termo $\dot{e}$ final, $e$ então se prorroga automaticamente, pleno jure, - orçamento do ano em curso. Só o véto revigora tal competência, para fim determinado.

Ora, se a 14 de novembro de cada ano a competencia orçamentaria da Assembléia se exaure pelo exercicio integral ou se perde por decadencia, em virtude de não uso, como poder-se-á pretender que essa mesma Assembléia, depois de 14 de novembro, possa ainda emendar o orçmento, para cujo trato ela já não tem mais poder?

Releva notar, como bem acentúa Planiol, que o termo final não comporta qualquer causa interruptiva, nem admite, em caso algum, a purgação da móra.

Nestas condições, parece evidente a impossibilidade de emenda ao orçamento, depois de publicado devidamente, quando já encerrado o praso de competencia do Legislativo. 
De resto, se fosse possivel a emenda, posterior à aprovação e publicação, para que haveria a lei constitucional de estabelecer um TERMO FINAL para o exercicio da competência da Assembléia? Como se conciliaria, do ponto de vista interpretativo dos textos constitucionais, a presença desse termo final com a faculdade de emenda? Para admitir a emenda, teriamos de concluir pela inoperancia do termo final estabelecido pela Constituição. Ora, a bôa hermeneutica não tolera que se conclúa pela inutilidade de qualquer dispositivo legal, a fortiori quando se trate de texto da Constituição. Dest'arte, ou o texto legal tem um sentido e um objetivo, e então a possibilidade de emenda não é de admitir-se; ou ela é de aceitar-se, mas haveremos de repelir por inutil o prazo estabelecido pelo artigo 32, na Constituição paulista. Ora, essa repulsa não é possivel, porque $o$ termo final assentado pela Constituição traz consigo uma consequencia das mais graves: a automatica prorrogação do orçamento vigente. Ele não é, na verdade, simplesmente preclusivo da competencia da Assembléia, mas, nos casos em que tal competencia não foi exercitada, ele acarreta uma consequencia juridica de suma importancia. Trata-se, pois, de termo final que não póde, sob pretexto algum, ser negligenciado ou relevado, porque a consequencia prorrogatoria se opera pleno jure.

3) O Direito orçamentario alienigena, por seu lado, não socorre a tése que pretende sustentar a possibilidade de emenda a um orçamento já votado, sancionado e publicado.

A verdade é que os autores nem sequer aventam tal possibilidade, tanto ela colide com a natureza das coisas e com os propositos legais de estabilidade do plano orçamentario, necessaria tanto ao Estado como ao contribuinte, para o qual é mesmo uma garantia individual.

Na França, com o proposito de aplicar um corretivo ao abuso dos creditos adicionais, chegou-se a estabelecer no artigo 32 do decreto de 31 de maio de 1862 que "le 
budget peut être rectifié, s'il a lieu, pendant le cours de l'exercice". Já desde a Constituição de 1852, em principio, os orçamentos retificativos eram autorisados, mas em realidade eles só chegaram a ser usados a partir de 1863.

A não ser na França, sómente na Italia, a partir da lei de contabilidade de 1883, codificada em 1884 (17 de fevereiro), foram encontrados orçamentos retificativos.

E' certo que tais orçamentos retificativos não eram bem exatamente a hipotese em exame, porque eles representavam mais do que a simples emenda. Entretanto, como os autores não nos dão noticia alguma de casos de emenda, examinamos o que dela mais se aproxima: os orçamentos retificativos.

Ora, mesmo a respeito desses o que consta é que só dois países os tentaram (França e Italia), tendo a experiencia resultado mal num e noutro. Na França, a partir de 1870 (eles haviam aparecido em 1863...) foram abandonados. E na Italia, segundo o testemunho de STourm, eles não preservaram o país "des excédents de dépenses et de la rupture de l'equilibre budgetaire, qui succéde bien malheureusement, dans ce pays, à une situation dont on admirait jusqu'alors la solidité progressive" (STourm op. cit., pgs. $343 / 346$, inclusive, nesta ultima, parte final da nota 14). Por essa razão, tambem na Italia, os orçamentos retificativos foram postos à margem das praticas financeiras correntes.

Não é aceito, portanto, na doutrina ou na legislação dos países mais conhecidos nada que se pareça com a pretendida emenda orçamentaria. A unica medida tentada, que poderia com ela ter algo de semelhante, foi dentro em pouco abandonada por inutil e nociva.

4) Saíndo do campo doutrinario e do terreno do direito constitucional patrio, vamos encontrar na nossa legislação ordinaria elemento de indiscutivel valor, em abono da tése, que sustentamos, da impossibilidade de emendarse o orçamento, depois de aprovado e publicado. 
Reside esse elemento no dispositivo do $\S 10^{\circ}$ do artigo 13 do decreto federal n. 4.536, de 28 de janeiro de 1922, já citado, decreto esse que organisou o Codigo de Contabilidade da União. Eis o que reza dito dispositivo:

"E' licito ao Governo retificar a PROPOSTA, em mensagem especial, ENQUANTO DEPENDE DE DISCUSSÃO NO CONGRESSO O PROJETO DE ORCAMENTO".

$\mathrm{O}$, texto é bastante claro e elucidativo, quando interpretado a contrario sensu. Se só é licito ao Governo retificar a proposta enquanto ela depende de discussão no Congresso, parece claro $e$ indiscutivel que, DEPOIS DE APROVADA DEFINITIVAMENTE, NÃO E MAIS LICITO PROCURAR RETIFICA-LA. O raciocinio é irrespondivel e se é verdadeiro para o orçamento federal, tambem o será para o estadual, porque os Estados, em materia orçamentaria, deverão obedecer a diretrizes gerais ditadas pela União (art. 5..$^{\circ}$ inciso XV alínea "b" da Const. Fed.).

\section{III - Da invocada jurisprudencia}

A mensagem do Governo do Estado, com a qual se encaminhou à Assembléia Legislativa o projeto que tomou o n. 664 de 1948, e através da qual foi pleiteado pelo Executivo, depois do dia 14 de novembro, após a aprovação e publicação do orçamento para 1949, um novo aumento no imposto de vendas e consignações, alude em certo ponto a dois acordãos em que pretende apoiar seus pontos de vista.

O primeiro desses acordãos é do Tribunal Federal de Recursos, proferido no recurso de mandado de segurança n. 90, publicado no "Diario da Justiça", da União em 6 de setembro deste ano, à pagina 2.555. E diz a mensagem referida : 
"Nesse julgado, contra o voto de um só dos Ministros, foi reconhecida a constitucionalidade da cobrança, a partir de $10^{\circ}$ de janeiro de 1947 , de adicionais ao imposto de renda, apesar de não revigorada expressamente a exigencia desses adicionais para o referido exercicio senão com a lei n. 81 , de 29 de agosto do mesmo exercicio e porque a lei orçamentaria n. 3, votada em 1946 ainda para o exercicio de 1947 contemplára, na receita, o tributo debatido" (Vide "Diario da Assembléia Legislativa", no "Diario Oficial do Estado", de 25 de novembro de 1948).

Para irmos por partes, examinaremos desde logo este acordão, para só depois passarmos ao exame do outro.

Antes de mais nada, cumpre acentuar que o acordão citado é unico. A mensagem não invocou outro sobre o mesmo assunto. E mister se faz recordar que não constitue jurisprudencia a existencia de um julgamento isolado. Póde ele ser fruto de maioria ocasional presente numa câmara julgadora, ou ainda ser decisão proferida em caso revestido de aspectos peculiarissimos, por isso mesmo inaplicavel a outros casos. A jurisprudencia é $-\operatorname{sim}-a$ cristalização de uma certa orientação, através de decisões repetidas, em tribunais e juizos varios, a respeito de hipoteses concretas semelhantes. Além disso, o acordão do Tribunal Federal de Recursos, citado pela mensagem governamental, era recorrivel, quer em face do artigo 101, inciso II, "a", da Constituição Federal, quer ainda em face do mesmo citado artigo 101, inciso III, alínea "a". E como sua publicação é recente, sendo datada de 6 de setembro p. p., é muito possivel, e até provavel, que o recurso tenha sido interposto para o Supremo Tribunal Federal e esteja ainda pendente de julgamento. A mensagem não esclareceu esse tópico de particular interesse para a autoridade do julgado que invocou. 
Mas, gratia argumentandi, vamos aceitar o acordão invocado como tendo escapado ao recurso certo da parte, passando em julgado.

Em tal caso, a primeira impugnação a ser feita à citação de dito acordão é a de que ele nada tem a vêr com $\square$ caso do aumento do imposto de vendas e consignações, porque ELE DECIDE SOBRE UMA HIPOTESE EXATAMENTE INVERSA. De fato: no caso do acordão invocado, HAVIA AUTORISAÇÃO ORCAMENTARIA para arrecadar-se o adicional sobre a renda no exercicio de 1947; o que faltava era a lei preexistente, porque esta criara o adicional para vigencia determinada e não havia essa vigencia sido prorrogada para 1947. No caso de agora, a hipotese é a oposta: se a Assembléia aprovar o aumento do imposto de vendas e consignações na base pedida pelo Governo, haverá lei concedendo o aumento, MAS FALTARÁ AUTORISAÇAOO ORCAMENTARIA PARA ARRECADAR DITO AUMENTO NO ANO DE 1949, PORQUE O ORCAMENTO JÁ SE ENCONTRA PERFEITO E ACABADO, não sendo cmendavel, como vimos.

Assim, no caso do acordão citado pela mensagem, tratava-se de uma omissão resultante de evidente engano ou desidia na prorrogação da vigencia do decreto criador do adicional. Mas a intenção de realizar essa prorrogação era tão manifesta que foi posta no orçamento a autorisação para arrecadar-se o adicional, como se ele houvesse sido efetivamente prorrogado. Foi por isso, talvez principalmente por isso, que o ilustre Tribunal Federal de Recursos entendeu de admitir a arrecadação do adicional, maximé tendo em conta que o orçamento autorizava tal arrecadação.

Outra circunstancia que se precisa ter em conta, ao apreciar-se a significação que o acordão citado pode ter como formador de jurisprudencia, é a seguinte: a não arrecadação do adicional sobre a renda, no exercicio de 1947, decorrente de um manifesto engano funcional, acarretaria à União o prejuizo pecuniario de varias centenas de milhões de cruzeiros. Concebeu-se, então, a idéia de que 
seria pagar muito caro por um simples engano, parecendo mais equitativo eliminar o prejuizo, ainda que com certo sacrificio da pureza dos principios e da meridiana clareza do texto constitucional. Querendo desfazer a impressão de que essa preocupação do imenso prejuizo pecuniario da União pesava no animo dos Juizes, o eminente relator do acordão deixou transparecer claramente que de fato estava com isso impressionado:

"Sr. Presidente, comenta-se que nos defrontamos com um desses casos apontados como instantes. $E^{\prime}$ e não é exato, sem que isso se torne contraditorio. Para alguns, este Tribunal deveria optar mais por um criterio de oportunidade do que pelo estritamente juridico, falando-se mesmo, em reforço, num apelo ao "salus populi suprema lex esto". Para outros, os juizes deveriam decidir limitandose ao papel de aplicadores mecanicos do direito positivo; nessa ordem de idéias até se falaria no "fiat justitia pereat mundus". Ambos os Iados exageram, data venia. E nesse, transbordamento compreensivel, mas não justificavel, dramatizam interesses que não impugnamos, mas que, em termos de serenidade, se reduzem a uma simples categoria técnica, na qual o direito revelando só precisa ser encarado tendo-se em mira um daqueles conselhos, etc. etc." (Diario da Justiça, federal, de 6 de setembro de 1948 , pg. 2.558).

Não queremos discutir a doutrina sustentada pelo voto vencedor desse acordão, que reputamos inaceitavel e perigosa, não só porque conclúe pela declaração de inutilidade do texto constitucional que exige lei vigente, anterior ao orçamento, criadora ou ampliadora do imposto, mas tambem porque dito acordão procura invalidar algo que a Constituição com toda razão considera como garantia individual. 
Insistimos apenas no carater especialissimo do caso concreto a que o acordão se referia e tambem à natureza particularissima E EXCEPCIONAL DA SOLUGÃO DADA POR ELE AO CASO CONCRETO.

E' o proprio voto do ilustre Relator que acentúa esse caráter excepcional da decisão, como a prevenir que ela NAOO DEVE CONSTITUIR PRECEDENTE INVOCAVEL:

"Só não é aconselhavel que se transforme em regra o excepcional acontecido na lei orçamentária n. 3, que só serviria para levar vento aos mónhos de tempestades francamente afastaveis: os individualistas jurídicos se lançariam sempre à controversia. Mais cuidado na política orçamentaria e sobretudo em sua elaboração nunca é demais nem subestimavel". (loco cit., pag., 2260, 3. coluna).

Sem precisar-se entrar no mérito desse julgado para refutar-lhe a doutrina, o que seria tarefa das mais faceis, levada a cabo, de resto, com concisão e brilho no voto do eminente Ministro Armando Prado, desde logo se vê que, mesmo nas palavras do eminente prolator do voto vitorioso, não ha alento para os designios da mensagem governamental, porque é esse proprio ilustre Relator quem adverte que o caso, por sua especialissima natureza, não deve constituir precedente capaz de firmar regra.

Vejamos agóra o que diz respeito ao acordão do Tribunal de Justiça de São Paulo, proferido no mandado de segurança n. 35.459.

Tambem a respeito desse aresto são cabiveis as observações iniciais que apresentamos atraz. Não se diz na mensagem a data de tal decisão, nem o lugar e dia de sua publicação. Não se informa se ela é definitiva ou ainda pendente de recurso, conquanto aí resida elemento de essencial importância para se inferir da autoridade da decisão invocada.

Mas admitamos tratar-se de acordão passado em julgado. 
A verdade é que nada tem ele a vêr com o assunto em exame aqui. Não é de ser invocado em abono da tése sustentada pela mensagem, segundo a qual "a autorização orçamentaria a que se refere a Constituição é qualitativa e não quantitativa".

No caso decidido pelo acordão citado, - di-lo expressamente a decisão - havia lei anterior instituindo o imposto e havia autorização orçamentária para arrecada-lo. Logo, estavam presentes as condições que o $\$ 34$ do artigo 141 da Carta Federal e o artigo 63 da Estadual desejam vêr reunidas. $E^{\prime}$ certo que o acordão, na parte final da citação feita pela mensagem, inclúe estas palavras:

“A previsão orçamentária, como é obvio, não é rígida; ao contrário, é elastica, podendo ser superada ou não atingida pela efetiva arrecadação, consequente dos lançamentos efetuados, para mais ou para menos" ("Diario da Assembléia Legislativa", de 25 de novembro de 1948).

Essas palavras do acordão, entretanto, apenas aludem a um fato real, de natureza evidente, que em absoluto não confirma a tése de que "a autorização orçamentaria a que se refere a Constituição é qualitativa e não quantitativa" O acordão citado não se reporta, no trecho referido, à autorização orçamentária, mas sim à previsão orçamentária. Esta ultima está relacionada com a PRODUTIVIDA$D E$ maior ou menor de um imposto, enquanto que a autorização orçamentária se reporta à legalidade, ou não, da exigencia fiscal, em face do $\S 34$ do artigo 141 da Constituição Federal e do artigo 63 da Carta Estadual. A previsão, como todo esforço humano de conhecimento de coisas futuras, é aleatoria e precária, dentro de certos limites; a autorização, para que o imposto póssa ser arrecadado legalmente, tem de ser um fato certo e incontestavel, constante de áto expresso do Poder competente. Como se vê, o acordão citado pela mensagem, ao aludir à PREVISÃO ORCAMENTÁRIA, estava se reportando a coisa completa- 
mente diversa da AUTORIZAÇÃO ORCGAMENTÁRIA, tendo ambos esses conceitos sido confundidos na mensagem, com sacrificio da bôa e exata terminologia financeira.

De resto, seria mesmo de estranhar-se que o acordão houvesse abonado a tése da mensagem. O texto do artigo $141 \S 34$ se refere à criação ou AUMENTO de imposto, feito por lei. Logo é o proprio texto que está dizendo que não é só a qualidade do imposto (ou melhor, a especie fiscal) que importa; tanto quanto a especie fiscal, importa tambem a magnitude do encargo (o aspecto quantitativo), porque a Constituição alude a ele expressamente, quando exige que tambem o AUMENTO seja estabelecido em lei. Dest'arte se vê que a alíquota do imposto (relação porcentual entre a riqueza tributada e a quantia efetivamente paga a título de imposto) importa tanto quanto a especis tributária. E nem podia deixar de ser assim. Que adiantaria exigir a lei autorização orçamentária para arrecadação válida de certa especie tributária, fazendo mesmo disso uma GARANTIA INDIVIDUAL, se deixasse ao sabor do Poder Público a alteração quantitativa do onus, através de uma modificação da alíquota durante o exercicio financeiro? Não ficaria o contribuinte descoberto contra o arbitrio? E não é esse arbitrio justamente que a lei deseja prevenir, dando ao contribuinte uma CERTEZA a respeito da magnitude do encargo que ele vai suportar, durante o exercicio, sob cada especie tributária autorizada no orcamento?

A magnitude da alíquota (que o vulgo e até mesmo muitas leis nossas chamam de "taxa do imposto", em lamentavel confusão terminologica) é elemento essencial na integração do requisito CERTEZA de que o imposto precisa revestir-se.

O velho mas sempre novo Adam Smith, ao formular as suas quatro regras classicas sobre o imposto, fez da certeza uma delas:

"The tax which each individual is bound to pay ought to be certain, and not arbitrary. The 
time of payment, the manner of payment, the QUANTITY TO BE PAID, ought all to be clear and plain to the contributor, and to every other person. Where it is otherwise, every person subject to the tax is put more or less in the power of the tax gatherer, who can either aggravate the tax upon any obnoxious contributor, or extort, by the terror of such aggravation, some present or perquisite to himself. The uncertainty of taxation encourages the insolence and favours the corruption of an order of men who are naturally unpopular, even where they are neither insolent nor corrupt. The certainty of what each individual ought to pay is, in taxation, A MATTER OF SO GREAT IMPORTANCE, THAT A VERY CONSIDERABLE DEGREE OF INEQUALITY, it appears, I believe, from the experience of all nations, IS NOT NEAR SO GREAT AN EVIL AS A VERY SMALL DEGREE OF UNCERTAINTY". (A. SMITH, "Wealth of Nations", ed. de The Modern Library, aos cuidados de Edwin Cannan, N. Y. pg. 778).

Melhor do que qualquer outro elemento, a citação do proprio texto smithiano esclarece a origem do requisito tributário da CERTEZA e explica porque é ele parte integrante desse conjunto de fatores que devem constituir uma garantia individual do contribuinte contra o Fisco. Se o propósito do texto constitucional é assegurar o cidadão contra o arbitrio, não adiantaria nada assentar somente a autorização qualitativa da especie tributária, porque a pressão do arbítrio se exercitaria no terreno quantitativo, durante o exercício.

Aí está porque o acordão citado, que como vimos se reporta à PREVISÃO ORCGMENTÁRIA, coisa muito diferente da AUTORIZAĞAOO ORCAMENTÁRIA, (embora a mensagem confunda as duas), nunca poderia ter desejado afastar do imposto o seu requisito de certeza, como elemento essencial à integração das garantias do contribuinte. 0 
Egregio Tribunal prolator do acordão citado será certamente o primeiro a admirar-se e, possivelmente, a assustar-se tambem, com o alcance e a interpretação que se pretendeu dar à decisão aludida.

Necessário não se faz ir além, para deixar patente a infelicidade da escolha dos julgados com que se pretendeu sustentar a pretensão manifestada pela mensagem governamental.

A jurisprudencia aduzida não se aplica ao caso examinado, porque trata de hipóteses diferentes, de caráter inteiramente excepcional, ou porque foi mal compreendida em seu alcance.

Passemos adiante. Ha um argumento último a que não desejamos deixar de aludir e que, a rigor, devêra ter sido levantado de início, porque é uma verdadeira preliminar.

\section{IV - 0 artigo 26 da constituição paulista}

“Os projetos rejeitados não poderão ser renovados na mesma sessão legislativa, a não ser mediante proposta subscrita por maioria absoluta da Assembléia".

Ora, dentro do prazo legal, o Governo do Estado remeteu à Assembléia Legislativa dois projetos estreitamente relacionados: um, o projeto de orçamento para o ano financeiro de 1949; outro, um projeto de lei encerrando providencias de caráter financeiro, a ser discutido e aprovado antes, afim de que as medidas por ele consagradas já pudessem ser aproveitadas no plano orçamentário.

Posto esse último projéto em discussão, o seu artigo relativo ao aumento da alíquota do imposto de vendas $\mathrm{e}$ consignações (aumento que era pleiteado na base de 2 para $3 \%$ ) sofreu uma emenda, por força da qual a elevação pleiteada foi concedida apenas em parte, E RECUSADA EM PARTE. Na realidade, a emenda aludida, que foi apro- 
vada, concedeu o aumento não de 2 para $3 \%$, como estava solicitado, mas na base de 2 para $2 \frac{1}{2} \%$. Logo, em relaçao a 0,5\% a ASSEMBLEIA LEGISLATIVA REJEITOU O PROJETO GOVERNAMENTAL HA QUESTÃO DE POUCOS $D I A S$. Essa rejeição, embora feita através de emenda subslitutiva ao texto do artigo, concedendo parte apenas do pedido, é patente, insofismavel. E sendo assim, em face dos expressos termos do artigo 26 da Constituição do Estado, parece evidente que a Mesa da Assembléia não póde receber o projeto, nem a casa poderá considera-lo objeto de deliberação, a não ser que êle apresente a assinatura de apoiamento de deputados que representem metade mais um do total de deputados componentes da Assembléia. Afóra nessa hipótese, não parece possivel seja renovada nesta mesma sessão legislativa, a discussão de $0,5 \%$ de aumento do imposto, ha poucos dias rejeitado pela Assembléia.

E é, então, de perguntar-se se a exigencia constitucional está no caso satisfeita, de modo a poder o projeto ter andamento válido.

Deante do que extensamente foi exposto e analizado, somos de parecer, salvo evidentemente melhor juizo, que depois de aprovado e publicado o orçamento para o ano financeiro de 1949, já não é possivel emenda-lo para o efeito de nele ser ainda incluida autorização para arrecadar-se o aumento de $0,5 \%$ no imposto de vendas e consignações, aumento esse que a Assembléia Legislativa venha porventura a conceder em face de solicitação do Poder Executivo. O dia 14 de novembro de 1948, relativamente à competencia orçamentaria da Assembléia Legislativa para o exercicio de 1949, é um termo final de caráter preclusivo. Nessa data, se a competencia foi exercitada, o orçamento votado se tornou validamente aceito; se não houvesse sido exercitada, o direito de exercita-la teria desaparecido por decadencia e o orçamento de 1948 se prorrogaria para o 
ano de 1949. De uma forma ou de outra, por exaustão, ou por decadencia, é certo, porém, que a Assembléia Legislativa do Estado, no que tóca ao orçamento de 1949, está com a sua competencia finalizada, não podendo tocar mais em dito orçamento, embora o mesmo, conquanto já aprovado e publicado, não entre em vigor senão a $10^{\circ}$ de janeiro de 1949. Só o veto, porventura oposto pelo Executivo ao orçamento, no todo ou em parte, teria a virtude de revigorar a competencia da Assembléia após o dia 14 de novembro, e isso mesmo para o fim determinado de examinar de novo a matéria vetada tão sómente. Mas o orçamento de 1949 não foi vetado. Ele foi sancionado e publicado. Consequentemente a preclusão da competência do Legislativo se tornou absoluta e irremediavel.

São Paulo, 10 de dezembro de 1948. 